\title{
Managing CMC-based Task through Text-based Dialogue: An Exploratory Study in a Chinese EFL Context
}

\author{
Lianfen Yu \\ School of Foreign Languages, Liaoning Normal University, China \\ 850 Huanghe Road, 116029, Dalian, China \\ Tel: 86-411-84570426E-mail: dlylf@hotmail.com \\ Gang Zeng (Corresponding author) \\ Department of School Education, Hyogo University of Teacher Education, Japan \\ 942-1 Shimokume, Kato, Hyogo, 673-1494, Japan \\ Tel.: 81-0795-44-2372Ｅ-mail: zenggang7@gmail.com
}

Received: June 13, 2011

Accepted: July 29, 2011

Published: December 1, 2011

doi:10.5539/elt.v4n4p221

URL: http://dx.doi.org/10.5539/elt.v4n4p221

\begin{abstract}
This paper examines EFL learners' dialogic interaction in the implementation of a computer-mediated communication (CMC) task. Within the framework of sociocultural theory, the research focuses on how learners working in pairs collaboratively perform task management and build relationship in the synchronous CMC context. Sixteen Chinese tertiary EFL learners in eight self-selected pairs worked on an assigned task in the online chat rooms. We had a descriptive analysis of the data obtained from online chat logs, focusing on the task-related talk and off-task talk. Results indicate that learners' task-related talk has a variety of functions and facilitates the establishment and maintenance of task intersubjectivity. The findings also reveal the positive role of off-task talk in facilitating this online learning activity.
\end{abstract}

Keywords: CMC, Text-based dialogic interaction, Task-related talk, Off-task talk, Intersubjectivity

\section{Introduction}

Peer interaction has been widely motivated in second language (L2) education and research. There is a general consensus among L2 educators and researchers on the importance of providing L2 learners with opportunities for meaningful interactions, in which they collaborate in constructing knowledge and achieve shared understanding. Arguably, the interactive learning experiences may lead to learners' more active contribution and cooperation, more independent decision making and greater sense of responsibility for their own learning. The authenticity of L2 learning can be achieved by assigning learners tasks in which the target language is both the medium and the goal. In so doing, the formal and functional features of language can be integrated into one activity that allows joint attention. Research evidence indicates that there is significant and positive relationship between collaborative peer interaction and L2 learning.

The development of computer-mediated communication (CMC) tools has made it possible to extend physical language classrooms to include a virtual learning space, in which learners interact both to learn and use the target language among themselves. This is particularly significant in English as a Foreign Language (EFL) context, where learners may not have sufficient opportunities to use English in dialogic processes outside class. CMC is defined by Herring (1996) as the "communication that takes place between human beings via the instrumentality of computers" (p.1, as cited in Murray, 2000, p. 399). In this paper, we will follow Murray's restricted definition of CMC to include only binary text-based modes, namely, Synchronous CMC or SCMC (e.g., chat rooms, Instant Messenger, etc.) and Asynchronous CMC or ACMC (e.g., email, bulletin board, etc.). The present research concerns the application of one mode of CMC, SCMC. Text-based SCMC (i.e., computer-mediated interaction via text message) presents a new hybrid form of communication that "combines the textuality of written communication with the real-time interactivity of face-to-face communication" (Darhower, 2002, p.250), thereby amplifying the visibility of language form and function and making language learning a more reflective process.

A wide range of research has explored the role of SCMC interaction in L2 learning. However, the majority of the 
studies are conducted within the framework of interactionist theory ((Blake, 2000; Morris, 2005; Pellettieri, 2000; Smith, 2003, 2004). Interactionist-based SCMC studies tend to focus on negotiation of meaning to the exclusion of other aspects of interaction while also ignoring learners' shared orientation to the task and each other. This reflects a reductionist view of interaction, oversimplifying the non-linear dynamic complexity of peer-peer interaction via this electronic medium. Thus, it is crucial to go beyond negotiated interaction to include the collaborative dimension of peer interaction in text-based SCMC context. Motivated by sociocultural theory (SCT), we assume it will be of great significance to explore how L2 learners' text-based dialogic interactions in the SCMC context can facilitate or debilitate shared understanding and joint implementation of the given tasks, and relationship building.

\section{Literature Review}

\subsection{L2 learning via Text-based SCMC}

With the development of CMC tools, computer assisted language learning (or CALL) is not just limited to human-computer interaction but expanded to include human-human interaction, and thus bring learners together to have meaningful interaction in the cyber space. Text-based SCMC is considered as "conversation in slow motion"

(Beauvois, 1992, p.455) or "reflective conversation" (Lamy \& Goodfellow, 1999, p. 43). The unique nature of the electronic exchanges within this new media enables users "to bridge the gap between oral and written communication" (Beauvois, 1998, p. 213) and allows for "more control of the conversation" (Okuyama, 2005, p. 5).

In text-based SCMC, learners solely rely on the written messages to sustain the flow of interaction, allowing more time to create, develop and refine the messages. This is especially significant for L2 learners who use the target language that they are still learning for communication. Additionally, the online exchanges can be stored in the courseware tools for teachers to track learner progress and provide feedback.

Despite the lack of social context cues (e.g., eye contact, nodding, and facial expressions) in this text-only medium, many researchers contend that social presence is an important concept in SCMC, which can function as a social medium that facilitates the creation and development of learning communities. Thus, participation in electronic discussion is no longer just a linguistic training, but a cultural and social practice (Hanna \& Nooy, 2003). Text-based language in this context can be a thinking tool to reflect on each other's language use and a socializing tool to facilitate mutual scaffolding for the completion of shared tasks, and thus "language learning and language socialization are interwoven into the fabric of CMC practices" (Shin, 2006, p. 77).

\subsection{Collaborative interaction and SCT}

SCT posits that social activity and mental activity are not separable entities but mutually constitute each other. According to SCT, learning is the internalization of social interactions. This process is mediated by cultural tools, of which language is the most important. Mediation via language occurs at two levels: social and individual. At social level, language functions as a social tool to establish and maintain a shared communicative context, in which learners co-construct knowledge and scaffold each other within their zones of proximal development (ZPD). ZPD is defined as "the distance between the actual development level as determined by independent problem solving and the level of potential development as determined through problem solving under adult guidance or in collaboration with more capable peers" (Vygotsky, 1978, p. 86). At individual level, language acts as a psychological tool to make sense of the collaborative learning process in the jointly created social environment, thereby facilitating the internalization of the co-constructed knowledge and regulating one's own mental world. SCT attaches great importance to the role of human agency, the mediated capacity to make meaningful choices within the affordances and constraints of a given context (Lantolf \&Thorn, p. 2006). Human agency plays a significant role in the process of internalization for learners, who are recognized as "agents-acting-with-mediational-means" (Wertsch, 1998).

The claim that language is learned best through interaction with other language users is supported by both cognitive interactionist approach and SCT. However, the two approaches differ in many crucial respects. Whereas the former views language acquisition as a linear input-intake-output cognitive process triggered by negotiation of meaning in interaction, the latter regards learning as a dynamic participatory process situated in social interactions. Thus, SCT argues for a reconceptualized view of interaction, one that considers interaction as not "simply a place for negotiation of meaning, but for collaborative construction of and engagement in activities" (Ohta, 1995, p. 96), and L2 learners as "neither processors of input, nor producers of output, but as ... [co-participants who] collaboratively produce utterances which they jointly own" (Ohta, 2000, p. 51).

SCT provides a valuable framework to examine interaction and its effect on language learning. Within this framework, the locus of language learning is not within individual's mind but in the participation of the socially mediated collaborative processes. More and more studies have challenged the interactionist view of L2 learning and begun to investigate learner language or learner dialogue for evidence of L2 development within the framework of 
SCT (e.g., Anton \& DiCamilla, 1998; Donato, 1994; Ohta, 1995, 2000).

Of particular significance in using language as both a cognitive tool and a social tool for interactive language learning process is the concept of Swain's collaborative dialogue. In collaborative dialogue, learners collaboratively use language "in problem solving and knowledge building" (Swain, 2000, p. 102). Learners' engagement in collaborative dialogue does not necessarily result from communication breakdowns, which require learners to negotiate for meaning to arrive at mutual comprehension; rather, it results from their shared orientation to the task goal, which encourages them to collaborate for better joint performance. Research has investigated how language learners, who can be "concurrently novices and experts" (Swain et al. 2002, p. 172), are mutually engaged in talking about language issues that emerge from interaction and benefit from this collaborative learning process. For example, Brooks and Swain (2009) examined the various sources of expertise (the prerequisite for the emergence of a ZPD). In their study, four adult ESL learners working in pairs engaged in a set of languaging activities when executing a collaborative writing task. The results showed that peer-peer interactions generated the most effective expertise with "one or the other of each pair taking on the role of expert... [and] become 'more expert'" (Brooks \& Swain, 2009, p. 79) and therefore afforded opportunities for learning. Employing the concept of collaborative dialogue, Zeng and Takatsuka (2009) investigated peer collaborative interactions in SCMC context. The findings of their study indicated that EFL learners, who worked in pairs in text-based online chat sessions, collaboratively used the target language to reflect on the target language use and their collaboration led to language learning.

\subsection{Task intersubjectivity}

SCT distinguishes between tasks and activities with the former referring to "behavioral blueprint" and the latter learners' actual performance (Coughlan \& Duff, 1994, p. 175). SCT proposes that task does not determine learner performance; rather, learners as agents construct task in their goal-directed activity (Roebuck, 2000). Thus, it is important that learners be viewed as agents who exercise their agency by constructing the task and making the task their own based on their own learning goals and interpretations of the task.

Successful implementation of task builds on the participants' mutual commitment to "a temporarily shared social world, a state of intersubjectivity" (Wertsch, 1985, p. 161). As an important concept in SCT, intersubjectivity is described as "shared understanding based on a common focus of attention and some shared presupposition that form the ground for communication" (Rogoff, 1990, p. 71). Wells (1999) argues that the establishment of intersubjectivity "involves both the psychological and social planes of participation" (p. 351). Previous L2 studies have demonstrated the important role of establishment and maintenance of task intersubjectivity during peer interaction in L2 learning (e.g., Anton \& DiCamilla, 1998; Guerrero \& Villamil, 2000). Research shows that Intersubjectivity can also be achieved in CMC context. For example, Darhower (2002), in examining the interactional features of SCMC, found that learners working in groups on communicative tasks could achieve and sustain intersubjectivity within the online social space.

\subsection{Task-related talk and off-task talk}

While research on collaborative dialogue has largely focused on language related episodes (or LREs), in which learners "talk about the language they are producing, question their language use, or other- or self-correct their language production" (Swain, 2001, p. 287), task-related talk and off-task task have received scant attention. In fact, task-related talk can help arouse learners' task awareness, and thus facilitate their control over the task. Among the few studies that have addressed the role of task-related talk in L2 learning process, Brooks and Donato (1994) reported that speaking in the dyadic interaction enabled their joint definition of task procedures and thus achieved intersubjectivity. They concluded that "task talk is in fact mediating the participants' control over the language and procedures of the task, each other and, ultimately the self" (p. 272). Even fewer studies have examined task-related talk in CMC context. Thoms et al (2005), the only study to our knowledge, examined how L2 learners use language to go about undertaking the task in an online chat activity. However, their research exclusively focused on learners' use of L1 that functions in different ways in facilitating the implementation of the task.

Previous research on the role of the off-task talk in the CMC context has produced conflicting results. While much of the research has argued for the negative impact of off-task talk on effective online discussion (e.g., Walther, 1996), recent studies have confirmed its positive aspect of off-task talk. For example, Chen and Wang (2009) investigated the social talk of high school students in the virtual discussion forums. Findings show that social talk is closely correlated with on-task talk and contributes to group learning. Little L2 research has addressed this issue in the CMC context. Therefore, there is a need to investigate the role of off-task talk in CMC-based L2 learning activity.

CMC allows for a more direct observation of the dialogic process. Therefore, our current study will go beyond LRE and highlight learners' task-related talk and off-task talk in the SCMC context. 


\subsection{Research questions}

Guided by the theoretical framework of SCT, we aimed to explore how learners collaboratively interact with each other to achieve the task goal in the computer-mediated context. The focus will be on the role of EFL learners' computer-mediated dialogues in performing task management and building relationships with each other. Specifically, these three questions will guide our research.

1. Do EFL learners use task-related talk in the SCMC context to mutually engage each other in an assigned language task?

2. How does the task-related talk function to facilitate the implementation of CMC tasks?

3. Do learners have off-task talk? If so, what role does it serve?

\section{Method}

\subsection{Participants and setting}

The present study is from a larger project, studying EFL learners' peer-peer dialogues in the CMC tasks. The participants of this study were 16 Chinese EFL learners, who were at the time studying in a second-year general English course at an education university in China. The mediation of instruction for the course was basically in the target language. All of them had studied English for at least seven years and were at an intermediate level of language proficiency. They were familiar and comfortable with the Internet and all had the experience of chatting online. In order to carry out this study, we created a website via Moodle, a free online course management system, in which the learners worked in eight chat rooms. With easy and widely available access to the Internet, the learners were expected to participate both on and off the university campus.

In the first week, we demonstrated how to use the Moodle tools and assigned a task for practice to familiarize the learners with the online learning environment. When learners felt comfortable with this online learning environment, we assigned them tasks that could be performed anywhere with access to the Internet. Each task was asked to be completed within about one hour. Each pair was allowed to fix their own time of meeting online. Use of English is encouraged but not required to implement the assigned tasks. As a requirement, they had to upload their joint work onto the website to conclude each task. All the learners were very cooperative and they completed the assigned task within the scheduled time frame. They seemed to have little trouble using the course site. All learners' online exchanges were stored in Moodle in a chronological order to be accessed at any time. Each of the participants' contribution was labeled with time and name.

\subsection{Task}

For this study, we examined learners' online activities when they worked on a text-reconstruction task, "in which students were presented with content words and had to insert function words (e.g., prepositions, articles) and change word forms (e.g., for tense morphology) to produce a meaningful and grammatically correct text" (Storch, 2002, p. 125). The task we employed is as follows:

Work in pairs and reconstruct the following text based on the content words.

zoo-keeper Japan kill himself. wife say he always take his job seriously. she tell police he recently look after four koala zoo responsibility make him very anxious. she say he worry koala get sick, this happened other zoo. police statement say man hang himself tree zoo.

It is worth mentioning that this traditional task was adopted and adapted to satisfy the three features required by collaborative tasks: working in pairs; producing a final product; and communicating both content and form (Swain, 2001). We considered using the collaborative task, as we believed it could help stimulate collaborative dialogue in this online learning environment. In fact, these three features have also found their way into recent CMC-based studies. Doughty and Long (2003), among many others, pointed out the disadvantages of large group interaction in text chat (e.g., the difficulty of following turn-taking rules) and argued that CMC discussion should be limited to two learners. Lee (2008) highlighted the importance of using tasks with a focus on both meaning and form in SCMC context. Hampel (2006) suggested that the task which requires learners to converge on a single goal is of particular benefit for CMC-based interaction. Thus, it is important that the collaborative tasks used in the SCMC context encourage learners' active involvement in the collaborative online pair work, facilitate their joint focus on the production of a text that meets the task requirements and draw their attention to both language meaning and form. Both the EFL instructor and the researcher agreed on the use of the task, which was further approved by another EFL researcher. 


\subsection{Data analysis}

When the online project was completed, all the chat sessions were downloaded for further analysis. We included both quantitative and qualitative data in our study. It is worth noting here that the quantitative data used in this study are purely descriptive and employed to inform our analysis. Data collection and analysis included two main stages. In the first stage, following Gánem (2006), we coded the data for language-related talk, task-related talk and off-task talk. We define Language-related talk (LRT) as talk about language use; Task-related talk (TRT) as talk related to task management and off-task talk (OTT) as talk irrelevant to the task (see Table 1).

In this study, we only focused on the latter two types of talk. For task-related talk, we examined them in three phases of task performance: task inception (starting of a task when the necessary conditions are met), task coordination (efforts of moving the task forward) and task completion (conclusion of the task when the goal is achieved). We did this in order to find how learners collaboratively start, proceed with and conclude each task. The first author transcribed all the data and the second author $25 \%$ of the data. The agreement rate between the two raters was $91 \%$. The second author also verified the transcription of the other $75 \%$ of the data by the first author. Disagreements were discussed until consensus was reached on the coding. In the second stage, we had a closer look at identified episodes and discussed their features and functions. Excerpts of some selected episodes will be presented to illustrate how the text-based talk reflects these functions. (Table 1 here)

\section{Findings}

\subsection{Existence of task-related talk}

As indicated from Table 2, altogether the 8 dyads spent $9 \mathrm{hrs}$ and 32mins on the task with an average of $1 \mathrm{hr}$ and $12 \mathrm{mins}$ per dyad, producing 649 turns of interactions with an average of 81 turns per dyad. In order to address the first research question, we counted the number of turns allocated to each of the three types of talk (i.e., LRT, TRT and OTT) in learners' online interactions. Turns were employed because they could be easily identified and could ensure the consistence of analysis. Results show that the percentages of coverage of the turns for the three types of talk are: $62.7 \%$ for LRE; $27 \%$ for TRT and $10.3 \%$ for OTT respectively. Interestingly, the percentage of TRT across all the 8 dyads does not vary much, ranging from 22.2 to $31 \%$. It is evident that all dyads working on the given language task did involve themselves in using text-based language for task management in this online learning environment.

Surprisingly, only one instance of use of L1 for task management process has been identified. That is to say, learners almost totally depended on L2 in task-related talk to mutually engage each other in moving the assigned task forward. Learners' reciprocal use of L2 to manage the task process was virtually spontaneous because they were not required to do so and none of the eight dyads negotiated the choice of language in carrying out the task. This result might have been transferred from their face-to-face class with English as the medium of instruction. Learners' exclusive use of L2 reflects their shared supposition of intersubjective conditions for this online communication. (Table 2 here)

\subsection{Functions of task-related talk}

In order to address the second research question, we examined the task-related talk in its three stages as mentioned above. We found during the stage of task inception, task-related talk serves two main functions: interpreting the task requirement and allocating roles. Excerpt 1 shows how the two learners interpret the task and reach the shared understanding of it.

\section{Excerpt 1}

10. Q: we will base on it to say a little story, right?

11. S: yes, like the first time.

12. Q: right.

13. S: we must try our best this time.

14. Q: I agree with you

15. Q: have you seen it over?

16. S: yes

17. Q: now begin!

Q first interprets the task instruction and asks $\mathrm{S}$ for confirmation (Turn 10). S confirms their shared understanding by referring to the first task, which is of the same type as the current one (Turn 11). This is also approved by Q (Turn 
12). Interestingly, they also encourage each other to contribute to the task (Turns 13 and 14). When they are sure that they are both cognitively and emotionally ready for the task, they start the task (Turn 17).

Evidence shows that learners tend to divide roles between themselves to fulfill responsibility for the completion of the given task. Excerpt 2 is an example in which the two learners negotiate the roles for the task.

Excerpt 2

4. A: let us begin

5. S: ok

6. A: do you say first?

7. S: yes

Evidently, learners employ task-related talk in this stage to mutually understand the task requirements and collaboratively determine role allocation. In so doing, they reciprocally engage in the joint pursuit of the task goal. This is in line with the statement, "Engagement does not come about until after several attempts to establish the students' own procedures for achieving their task-related goals" (Brooks \& Donato, 1994, p. 270). In this way, they are able to set the stage for task performance and make the task their own.

Task-related talk during the stage of task coordination is also characterized by two functions: negotiating turns and negotiating task procedures and demands. To keep the ball rolling, they collaboratively involve in turn taking management. They either assign turns to invite contribution or bid for turns to contribute. Expressions used include: "It is your turn, hurry up." "Could you like to do the next?" "It is my turn." In addition, they either ask their partners to slow down so that they can catch up or speed up so that they can finish the task on time. Exemplary utterances are "I am waiting for you." "Please wait." Evidently, these are all goal oriented. Through these turn taking mechanisms, they endeavored to move the task forward towards the task goal.

Besides turn negotiation, learners also negotiate task procedures and demands in this stage. Excerpt 3 demonstrates how learners negotiate task procedures when proceeding with the task.

Excerpt 3

5. T: First, the title should be.....?

6. Z: yes

7. Z: I am not sure, too

8. Z: let's chat about the content

9. T: How about "A Japanese zoo-keeper kill himself last night"?

10. Z: the title?

11. T: yes

12. Z: not interesting and striking

13. Z: I think we should talk about the passage

14. T: what should we write the title? I think we should write the title first.

15. Z: No, it wastes time

16. Z: and we can think the title while we talk

17. Z: ok?

18. T: we should finish the task around the title

19. T: or we may q

20. Z: what?

21. T: we may paoti do you understand?

22. Z: we can begin with "An zoo-keeper killed himself last night"

23. Z: I know.

24. Z: but it is hard for us to make it up right now

25. T: ok

26. Z: what about the first sentence 


\section{Z: it should be "A". sorry}

28. T: the first: Last night, a Japanese zoo-keeper killed himself in his home

\section{Z: THE TITLE IS THE STRESS KILLING MAN}

(underline mine)

In this episode, $\mathrm{T}$ asserts that they should come up with a title for the passage they are supposed to compose (Turns 5,11 and 14) so that they will not paoti (Chinese pinyin) meaning 'derail from the task' (Turns 18, 19 and 21). While sympathizing with T's proposal (Turn 23), Z, who does not agree (Turns 5 and 10), insists that it is hard to make it up right now and wastes time (Turns 15 and 24). She even rejects the title proposed by T (Turn 9) saying that it is not interesting and striking (Turn 12). She suggests that they think about the title while they talk. Finally, $\mathrm{T}$ makes a concession and accepts Z's suggestion (Turn 25). In response to Z's invitation of comment on her first sentence (Turn 23), T modifies it (Turn 25) and thus moves the task forward. In this way, they establish the task intersubjectivity. When they have finished reconstructing the text, $\mathrm{Z}$ suggests a title (using capital for emphasis) for the jointly composed text (Turn 114), which is confirmed by T. Interestingly, the two learners do not impose their ideas on each other but provide reasons for their ideas so that their ideas can converge for mutual construction of knowledge, making their interactions very explorative. The use of "we" or "us" $(n=11)$ indicates the activity is not an individual act but a collective conduct. Excerpt 4 is an example showing how learners negotiate task demands.

Excerpt 4

15. D: Recently, a zoo-keeper in Japan killed himself and nobody knew the reason.

Police statement said that the man hung himself on the tree in the zoo.

16. W: to tell you the truth, i thought it's a murder

$\cdots$

24. D: he was too anxious to kill [himself]

25. W: you want to let this to be the begaining of the story?

26. D: are you understand me

27. W: to kill what ??/ himself?

28. D: commit suicide

29. W: yeah, i know you want to state the task to be a general story

30. D: what do you think to the passage?

31. W: the main character can't stand the working stress?

32. W: i agree with you

33. D: ok

34. W: i just want to make a special story...

69. D: actually, i know your opinion now

70. D: haha

71. D: but i don't agree with you.

72. D: Ok, you write the beginning, let me see

$\cdots$

83. D: actually, you think too detail

84. D: are you agree with me

85. W: ok ok, let's make a general story, which just narrate the truth, not according to the detail, for example the reasons of the suicide

86. W: yes i agree with you

87. D: ok, let's finish it 
D first produces a sentence based on the original text (Turn 15). W shows disagreement with the content of the sentence concerning the reason for the death of the zoo keeper, thinking that it's a murder (Turn 16) rather than $a$ suicide. Clearly, she wants to go beyond the given passage and be more creative by analyzing what is behind the story and making a special story (Turn 34) instead of a general story (Turn 29). She tries to find the reason for the fact which is not included in the original text. In response, D does not concur, insisting complying with the task requirement (Turn71). He says to W, 'you think too detail' suggesting that she is off the track (Turn 83). Thus, the many turns of negotiating the content of the joint text to be written demonstrates their great difficulty in achieving intersubjectivity, that is, the shared understanding of the task. Each of them tries to persuade the other to accept his or her opinion. Even though this excerpt is illustrative of the feature of more conflict than cooperation, the two parties are trying to externalize their understandings of the task to each other in order to reach a consensus on this doing together. This process is very important for both the two learners to achieve a joint control over the task. Finally, W makes a concession and follows D's opinion (Turns 85 and 86). Once the intersubjectivity is established, the pattern of their interactions becomes more collaborative. This echoes Ellis's (2003) assertion that "learners may re-orientate to a task as the activity proceeds" (p. 199).

Learners' interactions also show their mutual caring and mutual assistance while they are on task. Excerpt 5 is one such an example. $\mathrm{Y}$ asks $\mathrm{X}$ to help her improve the sentence she has just created (Turns 50 and 52) and in response $\mathrm{X}$ provides an alternative (Turn 55). When $\mathrm{X}$ feels that $\mathrm{Y}$ is anxious (Turn 54), she tries to comfort $\mathrm{Y}$ (Turn 56).

Excerpt 5

50. Y: He worried the koalas get ill...I wonder if there is lack of any words

51. X: Lack what?

52. Y: Please help me.

53. X: but I don't know the correct sentence exactly...just a feeling...

54. Y: Oh, my god!

55. X: Maybe "He worried if the koalas get sick" is better.

56. X: Take it easy, Ying.

By negotiating task procedures and task demands, learners are able to stay on the same wavelength and thus create and maintain task intersubjectivity.

Analysis of the interactions in task completion stage shows that the task-related talk is employed to summarize and check the jointly produced work. This is their final collaborative effort in polishing their joint work.

Excerpt 6

89. Z: I send it to you

90. T: ok

91. Z: Last night, an old zoo-keeper called Japan killed himself in the zoo in Australia. His wife said sadly that he always took his job seriously. And she also told the police that recently the poor man had been looking after four koalas in the zoo. She said that he worried about the koalas of getting sick all the time. Because that had happened in the other zoos. It was said that the man was hanged himself on the tree of the zoo, according to the police's statement was the stress that killed him

92. Z: but there is something wrong in the sentence "BECAUSE........"

93. $\mathrm{T}$ : change "B" to $\mathrm{B}$

94. T: SORRY

95. T: change "B" to "b"

96. T: because this had

97. Z: it should be some koala had been ill in the other zoos

98. Z: but there doesn't conclude the "happen"

99. T: I think this "on the tree of the zoo" should be "on a tree of the zoo"

100. Z: yes

101. T: I don't know what you mean

102. Z: I agree with you to change the B into $b$

103. Z: ok?

104. Z: I send it to you

105. Z: ... She said that he worried about the koalas of getting sick all the time, because that had happened in 
the other zoos. It was said that the man was hanged himself on a tree of the zoo, according to the police's statement was the stress that killed him.

106. T: in the last [sentence] why you add "that"

107. Z: behind statement Is IT

\section{Z: I LOST IT}

\section{Z: THIS TIME IS OK}

\section{T: ok, we have finished it}

When the two learners have reconstructed the text sentence by sentence, $\mathrm{Z}$ puts all of them together and posts it for collective proofreading (Turns 89 and 90 ). After they have reviewed the joint production and made necessary corrections (Turns 92-103. Z posts the revised version again for the confirmation from $\mathrm{T}$ (Turns 104 and 105), who finds another problem which is subsequently resolved by $Z$ (Lines 106-108). Finally, the two learners are satisfied with their work and suggest the closure of the task (Turns 109 and 110). This episode reflects their collective effort in improving their joint performance. It is worth mentioning that quotation marks and capitals are used frequently to draw each other's attention.

\subsection{Off-task talk and its role}

Analysis shows learners do have off-task talk while working on the task. As table 2 suggests, seven out of eight pairs have off-task talk in their online interactions. It covers $10 \%$ of the total turns of the talk. Off-task talk emerges before, while and after they engage in the task. We identified tree types of off-task talk: greetings, leave takings and small talk. Most of the pairs greet each other when they enter the chat room and take leave of each other upon completion of each task. Small talk (the non-task related interactions in the process of doing the task) covers a variety of topics including the complaint of the unstable network, their feelings towards each other, and talk about their personal lives. In what follows, we will especially focus on how small talk functions to contribute to relationship building and the task execution.

Excerpt 7 demonstrates how learners feel about each other and the task in the off-task talk. A apologizes to S for her little contribution to the task (Turn 160), showing her sense of responsibility for the joint work. She also appreciates S's help and praises her as a good partner. In response, S positively comments on working with A on the task, saying that 'it is fun to do these' and 'it is a good way to improve [their] English.' Although the social talk appears to be unrelated to the task and does not directly contribute to learning, it does help to create and maintain an atmosphere of caring, trust and collaboration.

\section{Excerpt 7}

160. A: thank you, I find I do a little, sorry

161. S: not at all

162. S: it is fun to do these

163: A: the first word is "the"

164: A: ?

165: S: and it is also a good way to improve our English

166. S: thank $u$

167: S: I think it is fun to do the tasj

168. S: task

169: A: yes I think so. You help me a lot and I am very happy I have a good partner

170: S: thank $u$ it is my pleasure

Excerpt 8 reveals how learners bring their personal life into the off-task talk upon the completion of the task.

\section{Excerpt 8}

173. H. yes, I think it is good. I believe we do our best,

174. G: we did our best

175. H: thank you, you made our homework become better

176. G: thanx 
177. G: ... wish u a succeed in ur computer exam

178. H: I had finished my computer exam. I think maybe I cannot pass, because I think it is so difficult

179. G: I have confidence in $u$

180. H: thank you

When they finish their task, they positively comment on their joint work and the collaborative effort they make to accomplish the task (Turns 173 and 174). $\mathrm{H}$ especially acknowledges contribution from $\mathrm{G}$ in improving the task performance (Turn 175). In response, G expresses her appreciation (Turn 176) and wishes H good luck with her computer exam (Turn 177) and says that she has confidence in H (Turn 179). Obviously, the two learners use the off-task talk to "keep their self-esteem high after an experience where so many of their cognitive, affective, and social resources were at stake" (Guerrero \& Villamil 2000, p. 64). In this way, they strengthen the social bond between them and develop a sense of belonging and commitment to the assigned task and caring towards each other.

Evidence also shows that learners' orientation to the task goal enables them to have a better control over the off-task talk. The following excerpt shows how the two learners switch between off-task talk and on-task talk.

\section{Excerpt 9}

16. Y: I think the man must be a serious man. So if he has some important things, he will [feel] anxious

17. X: emm...maybe

18. Y: Poor man, I think.

19: X: well well $\sim$ to undertake the translation

20: Y: ok

$\cdots$

70: Y: Oh, I see. But I think he should not kill himself.

71: X: Oh?

72: $\mathrm{X}$ : Suicide is a way so-called to relieve stress.

73: Y: If you are he, what will you do? Suicide?

74: X: Life is just once. It's the most precious thing in the world, isn't it? So I won't do that.

In response to Y's expression of her personal feelings towards the man mentioned in the text (Turns 16 and 18), X brings her back to the task by asking him to undertake the translation (Turns 19 and 20). When they have almost finished the task, Y picks up the topic again (Turns 70, 72 and 73) and this time $\mathrm{X}$ cooperates by voicing her opinion (Turn 74). The transference between off-task talk and on-task talk indicate their interactions are both cognitively and socially oriented. This is in line with Chen and Wang's (2009) argument that "on-task and off-task talk not only co-occur, but also interweave to accomplish effective discussion and negotiation" (p. 608).

\section{Discussion and Conclusion}

This study set out to investigate the existence of task-related talk and its role in performing the task management in EFL learners' dialogic interactions promoted by an assigned task in the CMC context. Findings show that learners do employ task-related talk to lead each other towards the completion of the task. Analysis shows that learners are dialogically oriented to the assigned tasks as well as to each other. They do not start a task until they confirm the presence and readiness of their partners to participate. Similarly, they do not end a task until both of them believe they have achieved the task goal. In other words, both starting and ending of a task are jointly determined rather than unilaterally imposed. Their task coordination talk shows they mutually engage each other in moving the task along towards the task goal. All this reflects their shared responsibility and joint decision making. Thus, task-related talk functions in a variety of ways to establish, negotiate and maintain the intersubjectivity and facilitates learners' control over the task.

The study also set out to examine the presence of off-task and its role in the collaborative online learning activity. The results reveal that learners do have off-task talk to build up relationship with each other. From the selected episodes, we can see the off-task talk mirrors learners' mutual trust, caring and rapport. Through off-task talk, learners emotionally connect with each other and build positive interdependence, which might facilitate the creation of an inviting learning environment and the collaborative contribution to the task. Thus, although off-task talk is not directly relevant to the task at hand, it is significant in achieving the task goal.

To sum up, learners' text-based dialogue reflects both social and cognitive aspects of interaction. Learners take the 
online activity not just as a task-completion learning activity but also a relationship-building social activity, and these two activities constantly constitute each other.

Worthy of note is that very few instances of using L1 are identified in this study, making the target language both the goal and the medium of learning. This is in line with Ohta's study (1995) revealing that learners working in pairs use L2 for conversation and task management virtually without resorting to their L1. Another point worth noting is that learners are not always in agreement with each other over the solutions to the emerging language issues during interaction. This might provide learners with opportunities to experience "cognitive conflicts", which are perceived as a site of L2 learning as they can enhance their critical thinking when exposed to divergent opinions (Tocalli-Beller, 2003; Tocalli-Beller \& Swain, 2005).

The research has some pedagogical implications for the application of $\mathrm{CMC}$ in English language teaching. First, the study further proves that EFL teachers can use CMC to provide learners with an alternative learning space to carry out collaborative tasks, in which learners can make meaning of and in the target language. Second, it is important for teachers to know that learners can use target language to manage tasks in CMC context; Off-task talk is not all task-irrelevant and it may facilitate the successful task completion. Third, to render the learning activity more engaging, EFL learners should be assigned tasks requiring collaboration and allowed to structure tasks on their own. In this way, learners can be encouraged "to infuse activities with their own goals and procedures... [and thus they can] take control over them for themselves and have opportunities to gown into them" (Brooks \& Donato, 1994, pp. 273-274).

There are certainly some limitations in this research that should be acknowledged. Most importantly, the unstable network and the busy schedule might have affected learners' effective participation. Additionally, pairs in this study were mostly female-female and this might have affected the results. Further research should consider examining the effects of proficiency and gender differences on the text-based talk in the CMC context. Additionally, the comparison of peer-peer interaction in the $\mathrm{CMC}$ context and that in the face-to-face context is also worthy of investigation.

\section{References}

Anton, M., \& DiCamilla, F. (1998). Socio-cognitive functions of L1 collaborative interaction in the L2 classroom. The Canadian Modern Language Review, 54(3), 314-342. http://dx.doi.org/10.1111/0026-7902.00018

Beauvois, M. H. (1992). Computer-assisted classroom discussion in the foreign language classroom: Conversation in slow motion. Foreign Language Annals, 25(5), 455-464. http://dx.doi.org/10.1111/j.1944-9720.1992.tb01128.x

Beauvois, M. H. (1998). Conversations in slow motion: Computer-mediated communication in the foreign language classroom. The Canadian Modern Language Review, 54(2), 198-217

Blake, R. (2000). Computer-mediated communication: A window on L2 Spanish interlanguage. Language Learning \& Technology, 4(1), 120-136

Brooks, F. B., \& Donato, R. (1994). Vygotskyan approaches to understanding foreign language learner discourse during communicative tasks. Hispania, 77(2), 262-274

Brooks, L., \& Swain, M. (2009). Languaging in collaborative writing: Creation of and response to expertise. In A. Mackey \& C. Polio (Eds.), Multiple perspectives on interaction in SLA. New York: Routledge. pp. 58-89

Chen, F. C., \& Wang, T.C. (2009). Social conversation and effective discussion in Online group learning. Educational Technology Research and Development, 57, 587-612. http://dx.doi.org/10.1007/s11423-009-9121-1

Coughlan, P., \& Duff, P. (1994). Same task, different activities: Analysis of SLA from an activity theory perspective. In J. Lantolf \& G. Appel (Eds.), Vygotskian approaches to second language research. Norwood, NJ: Ablex. pp. 173-194

Darhower, M. (2002). Interactional features of synchronous computer-mediated communication in the intermediate L2 class: a sociocultural case study. CALICO Journal, 19, 249-277

de Guerrero, M. C., \& Villamil, O. S. (2000). Activating the ZPD: Mutual scaffolding in L2 peer revision. The Modern Language Journal, 84(1), 51-68

Donato, R. (1994). Collective scaffolding in second language learning. In J. P. Lantolf \& G. Appel (Eds.), Vygotskian approaches to second language research. Norwood, NJ: Ablex. pp. 33-56

Doughty, C. J., \& Long, M. H. (2003). Optimal psycholinguistic environments for distance foreign language learning. Language Learning \& Technology, 7(3), 50-80

Ellis, R. (2003). Task-based language learning and teaching. Oxford: Oxford University Press. 
Gánem Gutiérrez, G. A. (2006). Sociocultural theory and its application to CALL: A study of the computer and its relevance as a meditational tool in the process of collaborative activity. ReCALL, 18(2), 230-251. http://dx.doi.org/10.1017/S0958344006000620

Hampel, R. (2006). Rethinking task design for the digital age: A framework for language teaching and learning in a synchronous online environment. ReCaLL, 18 (1), 105-121

Hanna, B. E., \& de Nooy, J. (2003). A funny thing happened on the way to the forum: Electronic discussion and foreign language learning. Language Learning \& Technology, 7(1), 71-85

Herring, S. C. (1996). Computer-mediated communication: Linguistic, social, and cross-cultural perspectives. Amsterdam: John Benjamins.

Lamy, M. N., \& Goodfellow, R. (1999). Reflective conversation' in the virtual classroom. Language Learning \& Technology, 2(2), 43-61

Lantolf, J. P., \& Thorne, S. (2006). Sociocultural theory and the genesis of second language development. Oxford: Oxford University Press.

Lee, L. (2008). Focus-on-form through collaborative scaffolding in expert-to-novice online interaction. Language Learning \& Technology, 12(3), 53-72

Morris, F. (2005). Child-to-child interaction and corrective feedback in a computer mediated L2 class. Language Learning \& Technology, 9(1), 29-45

Murray, D. (2000). Protean communication: The language of computer-mediated communication. TESOL Quarterly, 34(3), 397-422

Okuyama, Y. (2005). Distance language learning via synchronous computer- mediated communication (SCMC): Eight factors affecting NS-NNS chat interaction. JALT CALL, 1(2), 3-20

Ohta. A. S. (1995). Applying sociocultural theory to an analysis of learner discourse: Learner-learner collaborative interaction in the zone of proximal development. Issues in Applied Linguistics, 6(2), 93-121

Ohta, A. S. (2000). Rethinking interaction in SLA: Developmentally appropriate assistance in the zone of proximal development and the acquisition of L2 grammar. In J. P. Lantolf (Ed.), Sociocultural theory and second language learning. Oxford: Oxford University Press. pp. 51-78

Pellettieri, J. (2000). Negotiation in cyberspace: The role of chatting in the development of grammatical competence. In M. Warschauer \& R. Kern (Eds.), Network-based language teaching: Concepts and practice. Cambridge: Cambridge University Press. pp. 59-86

Roebuck, R. (2000). Subjects speak out: How learners position themselves in a psycholinguistic task. In. J. P. Lantolf. (Ed.), Sociocultural theory and second language learning. Oxford: Oxford University Press. pp. 75-95

Rogoff, B. (1990). Apprenticeship in thinking. New York, NY: Oxford University Press.

Shin, D. (2006). ESL students' CMC practices: Context configuration. Language Learning \& Technology, 10(3), $65-84$

Smith, B. (2003). Computer-mediated negotiated interaction: An expanded model. Modern Language Journal, 87(1), $38-58$

Smith, B. (2004). Computer-mediated negotiated interaction and lexical acquisition. Studies in Second Language Acquisition, 26(3), 365-398

Storch, N. (2002). Patterns of interaction in ESL pair work. Language Learning, 5 (1), 119-158

Swain, M. (2000). The output hypothesis and beyond: Mediating acquisition through collaborative dialogue. In J. Lantolf (Ed.), Sociocultural theory and second language learning. Oxford: Oxford University Press. 97-114

Swain, M. (2001). Examining dialogue: Another approach to content specification and to validating inferences drawn from test scores. Language testing, 18 (3), 275-302

Swain, M., Brooks, L., Tocalli-Beller, A. (2002). Peer-peer dialogue as a means of second language learning. Annual Review of Applied Linguistics, 22, 171-85

Thoms, J., Liao, J., \& Szustak, A. (2005). The use of L1 in an L2 on-line chat activity. The Canadian Modern Language Review, 62, 161-182

Tocalli-Beller, A. (2003). Cognitive conflict, disagreement and repetition in collaborative groups: Affective and social dimensions from an insider's perspective. The Canadian Modern Language Review, 60(2), 143-71 
Tocalli-Beller, A., \& Swain, M. (2005). Reformulation: The cognitive conflict and L2 learning it generates. International Journal of Applied Linguistics, 15(1), 5-28

Vygotsky, L. S. (1978). Mind in society: The development of higher psychological processes. Cambridge, MA: Harvard University Press.

Walther, J. B. (1996). Computer-mediated communication: Impersonal, interpersonal and hyperpersonal interaction. Communication Research, 23(1), 1-43

Wells, G. (1999). Using L2 to master L2: a response to Antón and DiCamilla's Socio-Cognitive Functions of L1 Collaborative Interaction in the L2 Classroom. The Modern Language Journal, 83(2), 248-254

Wertsch, J. V. (1985). Vygotsky and the social transformation of mind. Cambridge, MA: Harvard University Press.

Wertsch, J. V. (1998). Mind as action. New York: OUP.

Zeng, G., \& Takatsuka, S. (2009). Text-based peer-peer collaborative dialogue in a computer-mediated learning environment in the EFL context. System, 37(3), 443-446

Table 1. Types of talk and examples

\begin{tabular}{ll}
\hline Types of talk & Examples \\
\hline Language-related talk (LRT) & $\begin{array}{l}\text { Ying: The “suicide" means “kill”, yes? } \\
\text { Xin: Yes, it means sb. kill himself } \\
\text { Xin: kills. Sorry }\end{array}$ \\
& $\begin{array}{l}\text { P: sounds good, it's time to hand our work to teachers, isn't it? } \\
\text { B: we should test our sentences and make them better. } \\
\text { P: Maybe you are right. } \\
\text { B: Let's see. }\end{array}$ \\
Off-task talk (OTT) & X: hello, so happy to see you on the internet again \\
\hline
\end{tabular}

Table 2. Summary of the results of learners' online talk

\begin{tabular}{llllll}
\hline & $\begin{array}{l}\text { Time spent } \\
\text { (Hrs: Mins) }\end{array}$ & $\begin{array}{l}\text { N. of turns } \\
\text { (total) }\end{array}$ & $\begin{array}{l}\text { N. of turns for } \\
\text { LRT }(\%)\end{array}$ & $\begin{array}{l}\text { N. of turns for } \\
\text { TRT }(\%)\end{array}$ & $\begin{array}{l}\text { N. of turns } \\
\text { for OTT (\%) }\end{array}$ \\
\hline Dyad 1 & $0: 56$ & 87 & $42(48.3)$ & $24(27.6)$ & $21(24.1)$ \\
Dyad 2 & $1: 30$ & 92 & $60(65.2)$ & $23(25)$ & $9(9.8)$ \\
Dyad 3 & $0: 58$ & 80 & $42(52.5)$ & $21(26.3)$ & $17(21.3)$ \\
Dyad 4 & $1: 28$ & 117 & $75(64.1)$ & $35(29.9)$ & $7(6)$ \\
Dyad 5 & $1: 20$ & 55 & $40(72.7)$ & $13(23.6)$ & $2(3.6)$ \\
Dyad 6 & $1: 04$ & 42 & $32(76.2)$ & $10(23.8)$ & $0(0)$ \\
Dyad 7 & $0: 46$ & 63 & $45(71.4)$ & $14(22.2)$ & $4(6.3)$ \\
Dyad 8 & $1: 30$ & 113 & $71(62.8)$ & $35(31)$ & $7(6.2)$ \\
total & $9: 32$ & 649 & $407(62.7)$ & $175(27)$ & $67(10.3)$ \\
average & $1: 12$ & 81.1 & 50.8 & 21.9 & 8.4 \\
\hline
\end{tabular}

